\title{
Rare diseases that mimic Systemic Lupus Erythematosus (Lupus Mimickers)
}

François Chasset ${ }^{1}$, Christophe Richez ${ }^{2,3,4}$, Thierry Martin ${ }^{4,5}$, Alexandre Belot ${ }^{6,7,8,9}$, AnneSophie Korganow ${ }^{4,5}$, Laurent Arnaud ${ }^{4,10,11^{*}}$

${ }^{1}$ Service de Dermatologie et d'Allergologie, Hôpital Tenon, AP-HP, 75020, Paris, France.

${ }^{2}$ ImmunoConcEpT, CNRS-UMR 5164 and Université de Bordeaux, 146 rue Léo Saignat, 33076, Bordeaux, France;

${ }^{3}$ Centre Hospitalier Universitaire de Bordeaux, FHU ACRONIM, Place Amélie Raba Léon, 33076, Bordeaux, France

${ }^{4}$ Centre National de Référence des Maladies Autoimmunes et Systémiques Rares Est SudOuest (RESO)-LUPUS, 67000 Strasbourg, France

5Service d'Immunologie Clinique Nouvel Hôpital Civil, 1 place de l'hôpital 67091

Strasbourg Cedex, France.

${ }^{6}$ Service de Néphrologie, Rhumatologie et Dermatologie Pédiatriques, Hôpital Femme MèreEnfant, Hospices Civils de Lyon,

${ }^{7}$ Université de Lyon, 59, boulevard Pinel, 69677 Bron cedex, France;

${ }^{8}$ Inserm U1111, 69007 Lyon, France;

${ }^{9}$ Filière des maladies autoimmunes et autoinflammatoires rares (FAI2R), 69677 Lyon, France

${ }^{10}$ Service de Rhumatologie, Hôpitaux Universitaires de Strasbourg, 67098 Strasbourg, France

${ }^{11}$ Université de Strasbourg, INSERM UMR-S 1109, 67000 Strasbourg, France.

\section{Auteur correspondant :}

Pr Laurent ARNAUD, Service de Rhumatologie, Hôpital de Hautepierre, 1 Avenue Molière BP 83049, 67098 Strasbourg Cedex. Secrétariat : 0388128474 | Fax : 0388128290 |

Laurent.arnaud@chru-strasbourg.fr 


\begin{abstract}
Several conditions have clinical and laboratory features that can mimic those present in Systemic Lupus Erythematosus (SLE). Some of these "SLE mimickers" are very common, such as rosacea which can be mistaken for the butterfly rash, while others such as Kikuchi disease, type-1 interferonopathies, Castleman's disease, prolidase deficiency, angioimmunoblastic T-cell lymphoma, Evans' syndrome in the context of primary immune deficiencies and the autoimmune lymphoproliferative syndrome are exceptionally uncommon. A proper diagnosis of SLE must therefore be based upon a complete medical history as well as on the adequate constellation of clinical or laboratory findings. While there is no single test that determines whether a patient has lupus or not, the search for auto-antibodies towards nuclear antigens is a key step in the diagnosis strategy, keeping in mind that ANAs are not specific for SLE. In case of persistent doubt, patients should be referred to reference centers with experience in the management of the disease.
\end{abstract}

Keywords: Lupus Erythematosus, Systemic / Diagnosis, Differential / Diagnosis / Review 
The term "lupus", the Latin word for wolf, has been used since the early Middle-age to describe a chronic skin disease with lesions said to resemble wolves' bite. During the following eleven centuries many different entities were included erroneously under that term, such as cutaneous tuberculosis (lupus vulgaris) or sarcoidosis (lupus pernio). The term lupus erythematosus (LE) was coined by Cazenave in 1851, while it was recognized at the very end of the $19^{\text {th }}$ century that some individuals with LE also suffered from internal organ manifestations, hence the term Systemic Lupus Erythematosus (SLE). Following major advances in immunology during the $20^{\text {th }}$ century, SLE -the "disease with a thousand faces"-, was fully recognized as a systemic autoimmune disease characterized by the production of auto-antibodies against nuclear antigens in association with a broad spectrum of clinical and laboratory manifestations. The disease can affect almost any tissue or organ system. Its presentation and course are highly variable, with symptoms ranging from minimal to lifethreatening. In addition to differences in disease epidemiology (1), marked ethnic variation in organ involvement has also been reported. For many decades, the distinctions between SLE and other autoimmune diseases remained a matter of the clinician's individually applied diagnostic skills, creating difficulties in the comparability across clinics, specialties and nations (2). In order to facilitate such comparisons, classification criteria for were derived for SLE in 1972 and subsequently revised in 1982, 1997, 2012 and very recently 2017. The latest revision of these criteria requires the presence of antinuclear antibodies (ANA) at a titer $>1: 80$ for a patient to be classified as having SLE (3). Yet, several other conditions (table 1) exhibit clinical and laboratory features, including the occasional presence of ANA, that can mimic those present in patients with SLE. Those conditions, including common skin diseases, Kikuchi disease, the hemophagocytic lymphohistiocytosis, type-1 interferonopathies, Castleman's disease, prolidase deficiency, angioimmunoblastic T-cell lymphoma, Evans' 
syndrome in the context of primary immune deficiency and autoimmune lymphoproliferative syndrome, will be reviewed hereunder.

\section{Cutaneous mimickers}

Specific cutaneous findings are present in $75-80 \%$ of SLE patients (10). In 1981 Gilliam and Sontheimer proposed a classification scheme which discriminates between lupus specific and lupus non-specific cutaneous lupus erythematosus (CLE) (11). Correct diagnosis of CLE may be difficult because of the broad clinical spectrum of CLE subtypes. Moreover, about one third of patients may have two or more CLE subtypes during the course of their disease (12). Many other conditions can mimic specific findings of CLE depending on CLE subtypes (Table 1). In most of cases, cutaneous biopsy with histopathologic findings allows to rule out differential diagnoses. Typical histological features of CLE include interface dermatitis consisting of a mononuclear cell infiltrate at the dermo-epidermal junction, basal layer degeneration, perivascular and peri-adnexal inflammation, mucin deposition, and hyperkeratosis (13). Direct immunofluorescence of lesional skin showing deposition of immunoglobulin (often $\mathrm{IgG}$ ) and complement components (often C3) at the dermal-epidermal junction (the so-called lesional lupus band test) may be useful in equivocal cases. However, a positive lupus band test may be observed in sun-damaged skin or other skin diseases and is therefore not diagnostic for CLE (14). Several differential diagnoses may have significant clinical and histopathological overlap with CLE (Table 2). In these cases, CLE diagnosis may be very challenging and a clinic-pathological confrontation is necessary. A typical example is the differentiation between CLE and rosacea. Usually, the topography of lesions and the presence of pustules allow ruling out the diagnosis of CLE easily but both conditions may present with inflammatory papules and/or facial erythema and both are exacerbate after sun exposure (15). Histologically, perifollicular and perivascular lymphocytic infiltrates are 
characteristic features of the two diseases (15). Recently, in equivocal cases, the presence of plasmacytoid dendritic cells assess by CD123 immunostaining has been shown to be a reliable tool to discriminate between CLE and rosacea (15), localized DLE of the scalp versus lichen planopilaris, LE panniculitis versus Subcutaneous Panniculitis-like T-Cell Lymphoma, diffuse acute CLE versus dermatomyositis.

\section{Viral infections}

Several features such as fever, rash, lymphadenopathy, lymphopenia, or mucosal ulcerations are common to SLE and viral infections. The initial distinction between both can be therefore be difficult (16), with the occasional presence of antinuclear antibodies during viral infections. A related question is to determine whether viral infections may contribute to the pathogenesis of SLE, as many pathogens are known to contribute to abnormal immune responses in genetically susceptible individuals, through molecular mimicry, epitope spreading, or bystander activation (17). Additionally, the accumulation of endogenous viral products might trigger the production of interferon, a key cytokine in SLE (17). Common viruses, such as Epstein-Barr virus (EBV), parvovirus B19, cytomegalovirus, retroviruses have therefore be suggested as potential triggers for SLE. More specifically, it has long been shown an association between SLE and an increased EBV seropositivity and viremia, with functionally impaired EBV-specific CD8+ T cell responses in SLE patients (18).

\section{Type I Interferonopathies}

Type-I interferon (IFN) appears within the last few years as a central cytokine in lupus, capable to promote loss of tolerance by activating autoreactive B and T cells (19). AicardiGoutières Syndrome (AGS) was first identified as a disease affecting neonates and mimicking a congenital viral infection. Patients were characterized by an increase of type-I IFN activity 
in the cerebrospinal fluid and serum. Interestingly, some patients presented later in life symptoms of systemic autoimmunity fulfilling the criteria for SLE. This neuroinflammatory disease has been genetically elucidated in the mid-2000s with the identification of TREX1 deficiency as the first Mendelian cause of the so-called type I interferonopathies. TREX1 encodes for an endogenous nuclease, which is involved in the elimination of nucleic acids within the cytoplasm, and prevent the activation of innate immune sensors. In case of biallelic mutations, this enzyme defect leads to an accumulation of endogenous nucleic acids and a subsequent detection by the innate sensor of a danger signal priming a type-I IFN production. To date, a total of 9 genes have been reported as being responsible for type-I interferonopathies with lupus-like syndrome, in addition to complement-related genes. However, The clinical spectrum of those type I interferonopathies is extremely variable (table 3) and encompasses neurological symptoms ranging from neonatal encephalopathy to isolated cerebral calcification and includes spastic paraparesis as well as inflammatory manifestations from chilblain lupus to SLE with antinuclear and anti-DNA antibodies. While those diseases can be considered within the spectrum of SLE, the importance of a proper differential diagnosis compared to "common" SLE is the possibility to go through personalized treatment blocking the IFN signaling pathway (20). The diagnosis of these inborn anomalies of the immune system is difficult with type-I interferonopathies being suspected in case of early onset or when the familial past medical history is evocative. To date, the detection of IFN itself is still difficult as only a few femtograms per $\mathrm{ml}$ are circulating in patient's sera. Promising results have been shown from the SIMOA® (single molecule arrays) strategies, which may represent an option in the next future. Another test known as the IFN signature score comprises the expression by qPCR of 6 IFN-inducible genes (IFI27, RSAD2, IFI44L, ISG15, IFIT1 and SIGLEC1) (21). The score is high and remains high in most of type-I interferonopathies independently from disease activity. In addition, patients with isolated 
neurological symptoms (in the family of a SLE patient for example) may display a positive signature, even in the absence of any autoimmune symptoms. This positivity in the relatives is highly evocative for genetic type-I interferonopathies. At the end, genetic screening is mandatory to confirm the diagnosis.

\section{Hemophagocytic lymphohistiocytosis}

The macrophage activation syndrome (MAS) bears a close resemblance to a group of histiocytic disorders known as hemophagocytic lymphohistiocytosis (HLH). Those are a group of potentially life-threatening hyperinflammatory syndromes characterized by a set of non-specific clinical and laboratory features (table 4) with inconstant histiocyte proliferation and haemophagocytosis (22). The term hemophagocytosis describes the histological finding of activated macrophages engulfing erythrocytes, leukocytes, platelets, and their precursor cells. MAS can mimic a SLE flare because the two entities share some common features including fever, lymphadenopathy, splenomegaly, rash, neurologic symptoms and blood cytopenias. Noteworthy, MAS is a known complication of SLE and in such cases is frequently inaugural (onset of MAS and first SLE flare are simultaneous). This overlap in clinical presentations can hinder the recognition of incipient MAS and delay the selection of the most appropriate therapeutic approach. HLH can be familial or sporadic. It most frequently affects children before 2 years of age but it is also observed in older children as well as in adults of all ages. HLH is designated as "primary" or familial HLH, when there is a familial history of HLH or a known underlying genetic defect such as perforin gene mutations. "Secondary" or sporadic HLH can occur during systemic infections (in particular with Epstein-Barr virus or cytomegalovirus), malignancy, and rheumatic disorders such as Still disease or SLE. The term MAS is frequently used when HLH is associated with a rheumatic disorder. HLH usually presents as a febrile illness associated with multiple organ 
involvement. Skin manifestations are varied and frequent. They include maculo-papular rashes, purpura, and edema. Neurologic symptoms have been reported in 30 percent of cases and include seizures, confusion, demyelinating lesions and aseptic meningitis. Cytopenias especially thrombocytopenia, anemia and neutropenia are seen in greater than 80 percent of patients. Consequently, differential diagnosis with a lupus flare may be difficult especially early after disease onset, whereas prompt instauration of adapted treatment is essential for patient survival. Awaiting for anti-nuclear antibodies testing implies unsatisfactory delay and is useless in patients with preexisting lupus. Diagnostic criteria for HLH have been proposed in 2004 by the HLH Study Group of the Histiocyte Society (23) but are only validated for children. The most fast discriminating test is most certainly the demonstration of tissue hemophagocytosis usually by a bone marrow aspirate. In our series the sensitivity of this criterion reached almost $100 \%$ but others have shown that failure to demonstrate bone marrow haemophagocytosis should not exclude the diagnosis. We have recently reported the largest series of MAS episodes in SLE adult patients (22). We have identified the most remarkable clinical and biological features that should raise suspicion of MAS because they are rare in common lupus flares. We think that these features can also be used for early differential diagnosis between HLH and SLE. They include high fever (in particular $>39^{\circ} \mathrm{C}, 90 \%$ of patients), neurologic symptoms (confusion, seizures), neutropenia (in particular $<1000 / \mathrm{mm}^{3}$ observed in more than $40 \%$ of patients) as well as significant increases in the levels of ASAT, $\mathrm{LDH}$, ferritin, and procalcitonin. These last laboratory features are not commonly high during lupus flare. Almost $100 \%$ of patients presented increased ASAT with a median over 5 times the upper limit of normal values whereas liver enzyme abnormality due to lupus have been reported in no more than 5 percent of cases. Hyperferritinemia assessed using the threshold of $>500 \mu \mathrm{g} / \mathrm{L}$, had the best sensitivity $(96.2 \%)$ among common laboratory features analyzed, and appeared as the strongest indicator to separate MAS from active SLE in another series (24). 
Low fibrinogen and elevated serum triglycerides are also suggestive of HLH. Immunologic studies such as serum soluble IL-2 receptor, NK cell functions and CD8 T cell activation are not widely available and therapy should not be delayed while awaiting results of these testings.

\section{Autoimmune lymphoproliferative syndrome}

Autoimmune lymphoproliferative syndrome (ALPS), also known as Canale-Schmitt syndrome, is caused by FAS/TNFRSF6 deficiency (25). ALPS-FAS is characterized by early onset non-malignant lymphadenopathies and splenomegaly and multilineage peripheral cytopenia due to immune destruction or to splenic sequestration (26). There is an increased risk of B-cell lymphoma and the disease is typically characterized by the accumulation of a polyclonal mature double negative T cell population (TCR $\alpha \beta$, CD3+ CD4-CD8-, >1.5\% of total lymphocytes or $2.5 \%$ of CD3+ lymphocyte counts). Patients can be diagnosed with antinuclear and anti-dsDNA antibodies. Some of them develop lupus nephritis, even in adult life. Interestingly, FAS, FAS ligand deficiency is associated in mice with a lupus-like disease (MRL/lpr). Most cases of ALPS-FAS in humans result from dominant heterozygous germline FAS mutations, leading to an impaired apoptosis of $\mathrm{T}$ cells during the negative selection process in the thymus. Autoreactive $\mathrm{T}$ cells and abnormal $\mathrm{T}$ cells can thus provide help to surviving autoreactive B cells with lymphoproliferation and autoimmune disorders. However, rare homozygous mutations can be observed. In some patients genetic diagnosis is difficult because of the occurrence of somatic mutations or a combination of heterozygous germline and somatic mutations in cases of haploinsufficiency. Plasma biomarkers are currently used for the prediagnosis of ALPS-FAS and include soluble FAS ligand, interleukin-10, and vitamin B12 dosages. Immunoglobulin levels are usually normal or elevated. Autoimmune cytopenia occur in more than $50 \%$ of cases. As young patients with SLE often present with 
severe systemic disease, lymphadenopathies, splenomegaly and cytopenia, ALPS is an important differential diagnosis influencing therapy. Rapamycin improves disease activity and associated autoimmune cytopenia (27).

\section{Primary immunodeficiencies}

PIDs (Primary immunodeficiencies) are inherited diseases associated with an increased risk of infections. Up to 300 genetic defects are known to cause PIDs, with features of immunodeficiency and in many cases possible autoimmunity or autoimmune diseases (28). SLE per se is not so frequent during PIDs. Reports of SLE like-diseases have been observed in CD19 heterozygous defects, and indeed associated with well-known heterozygous or homozygous complement deficiencies and in monogenic forms of SLE (see interferonopathies). Furthermore, in PIDs, the risk of autoimmune cytopenia is at least 120 higher than in the general population and nearly all types of PIDs involving B or T cells are concerned (B-cell CVID, Rag deficiencies, NFKB deficiencies, etc.). Thus, especially in early onset autoimmune hemolytic anemia, immune thrombocytopenia, or Evans syndrome, juvenile form of SLE should be suspected but the unusual occurrence of infections, profound lymphopenia, or hypogammaglobulinemia, or a suggestive family context, should alert about PID, leading to appropriate genetic analysis (targeted or whole exome sequencing) In this view, defects affecting regulatory $\mathrm{T}$ cells, as LRBA or CTLA4 deficiencies are frequently complicated with Evans syndrome. Indeed, immunosuppressive therapies can make worse the immune defect. Intensive therapy as bone marrow transplant or more targeted therapies like rapamycin, or therapies restoring the CTLA4 pathway (abatacept, hydroxychloroquine) should be discussed depending of the PID.

\section{Kikuchi disease}


Kikuchi disease (KD), also called Kikuchi-Fujimoto disease or Kikuchi histiocytic necrotizing lymphadenitis, is a condition of unknown cause usually characterized by cervical lymphadenopathy and fever. It may mimic more chronic conditions, including SLE. The exact difference between both diseases is still confusing, and the question of whether histiocytic necrotizing lymphadenitis in SLE should properly be regarded as SLE with lupus lymphadenitis, or as isolated KD mimicking SLE, remains unresolved (29). Indeed, KD shares sex, age predisposition and some clinical manifestations with SLE, as well as histologic features. On the other side, biopsy of the lymph-nodes associated with SLE displayed, in $20 \%$ of cases, histological and ultrastructural findings indistinguishable from KD. In a retrospective literature review (30) that described 244 patients with KD, the most common signs and symptoms were: lymphadenopathy (100\%), fever (35\%), rash (10\%), arthritis (7\%) and fatigue (7\%). All these symptoms are diagnostic criteria for SLE. Furthermore, various skin manifestations have been described including facial erythema, erythematous lesions, ulcers, leukocytoclastic vasculitis, alopecia and oral ulcerations (31). But, the presence of a malar "butterfly rash" should raise the diagnosis of SLE. Lymph node involvement is usually cervical and localized in KD. The nodes are usually only moderately enlarged (1 to $2 \mathrm{~cm}$ in diameter) but occasionally are much larger $(\leq 7 \mathrm{~cm})(32)$. They are typically firm and mobile. The nodal enlargement is often associated with acute pain. $12-59 \%$ of patients with SLE develop lymphadenopathies at some point during the course of the disease. Those adenopathies measure around $1 \mathrm{~cm}$, are painless, and associated with disease activity. The majority of patients with Kikuchi disease have a normal complete blood count (32), although cytopenia are not infrequent. Anti-nuclear antibodies are positive at the time of diagnosis in $30 \%$ of patients with KD (32). However, anti-dsDNA or other antibodies directed against extractable nuclear antigens are generally negative. These tests should be performed in patients with suspected Kikuchi syndrome who have features suggestive of SLE in order to 
exclude this diagnosis. The diagnosis of Kikuchi disease is made by lymph node biopsy. Biopsy should be performed, despite the self-limited nature of this syndrome, in order to exclude more serious conditions requiring aggressive therapy such as lymphoma. In KD, lymph-node displayed the following histological findings: patchy paracortical necrosis, histiocytes with crescentic nuclei and other cells (predominantly T-cells), karyorrhexis, and scarce plasma cells in the absence of neutrophils and granulomas (33). In SLE, hematoxylin bodies and plasma cells are also seen, and could help to make the difference between both diseases. Finally, patients with KD that mimics SLE, relapse more frequently than regular KD and should be managed like SLE.

\section{Castleman's disease}

Multicentric Castleman disease (MCD) is a rare and life-threatening disorder involving systemic inflammatory symptoms, polyclonal lymphoproliferation, cytopenias, and multiple organ system dysfunction caused by a cytokine storm often including interleukin-6 (34). Human herpes virus-8 (HHV-8) drives the hypercytokinemia in all HIV-positive patients and some HIV-negative patients. There is also a group of HIV-negative and HHV-8-negative patients with unknown etiology and pathophysiology $(34,35)$. Characteristic histopathologic features may include regressed or hyperplastic germinal centers, follicular dendritic cell prominence, hypervascularization, and polytypic plasmacytosis (34). Clinical hallmarks include fever, night sweats, lymphadenopathy, ascites and hepatosplenomegaly. Laboratory findings commonly include elevated erythrocyte sedimentation rate, C-reactive protein, fibrinogen and anemia; positive anti-nuclear antibody, anti-erythrocyte autoantibodies, and anti-platelet antibodies; and proteinuria, hypoalbuminemia, polyclonal marrow plasmacytosis, polyclonal hypergammaglobulinemia, and thrombocytosis or thrombocytopenia. An international working group has recently derived classification criteria for the disease (34). 
Patient with an overlap of SLE and MCD have been reported, therefore MCD is potentially both an associated and differential diagnosis of SLE.

\section{Angioimmunoblastic T-cell lymphoma}

Angioimmunoblastic T-cell lymphoma (AITL) is an uncommon subtype of mature peripheral T-cell lymphoma (36). The main clinical manifestations are fever, unintentional weight loss, night sweats, lymphadenopathy and less commonly hepatomegaly. A rash can be seen in $20 \%$ to $50 \%$ of AITL patients and has been reported as morbilliform, urticarial, or more polymorphic (37). The main laboratory findings include elevated lactate dehydrogenase levels, inflammatory syndrome, hypergammaglobulinemia, anemia, and lymphopenia. Autoimmune manifestations such as autoimmune hemolytic anemia, thrombocytopenic purpura or vasculitis are reported in one-third of patients. Early stage AITL is very uncommon with nearly $70 \%$ of patients having bone marrow involvement at presentation. The overall prognosis for AITL remains poor with a 5-year median survival of $32 \%$. In several clinical trials, recently approved drugs with known activity in AITL are paired with induction regimens with the hope of demonstrating long-term progression-free survival. The treatment of relapsed or refractory AITL remains an unmet need (36).

\section{Prolidase deficiency}

Prolidase deficiency (PD) is an autosomal recessive disorder characterized by recurrent skin ulcerations, chronic dermatitis, chronic infections (ear, sinus, and lung), hepatosplenomegaly, facial abnormalities, grey hair, bone demineralization, chronic joint dislocations, and mild mental retardation (38). Anemia, thrombocytopenia, hypergammaglobulinemia, and hypocomplementemia are common, and can lead to an erroneous initial diagnosis of SLE. The diagnosis of PD is made by chromatography of urinary amino acids, which reveals an 
important excretion of iminodipeptides. An association between systemic lupus erythematosus (SLE) and prolidase deficiency has been reported (39). No curative treatment is yet available for PD.

\section{Conclusions}

Diagnosing lupus can be challenging because several conditions have clinical and laboratory features that can mimic those present in SLE. Some of these "SLE mimickers" are very common, such as rosacea which can be mistaken for the butterfly rash, while others such as ALPS are exceptionally uncommon. A proper diagnosis of SLE must therefore be based upon a complete medical history as well as on the adequate constellation of clinical or laboratory findings. While there is no single test that determines whether a patient has lupus or not, the search for auto-antibodies towards nuclear antigens is a key step in the diagnosis strategy, keeping in mind that ANAs are not specific for SLE. In case of persistent doubt, patients should be addressed to reference centers with experience in the management of the disease.

\section{Disclosures:}

- François CHASSET has received honoraria (Speaker's bureau, travel grands and/or funded research) from GSK.

- Laurent ARNAUD has received honoraria (Speaker's bureau, travel grands and/or funded research) from Amgen, Astra-Zeneca, BMS, Chugaï, GSK, Janssen-Cilag, Lilly, LFB, Menarini France, Roche, Pfizer, UCB.

- Thierry MARTIN has received honoraria (Speaker's bureau, travel grands and/or funded research) from Actelion, Amgen, BMS, Chugaï, CSL Behring, GSK, Genzyme, Janssen-Cilag, LFB).

- Alexandre BELOT has received honoraria (travel grants or funded research) from Novartis, Merck, Sobi, Octapharma, Roche. 


\section{References}

1. Arnaud L, Fagot JP, Mathian A, Paita M, Fagot-Campagna A, Amoura Z. Prevalence and incidence of systemic lupus erythematosus in France: a 2010 nation-wide populationbased study. Autoimmun Rev. 2014;13(11):1082-9.

2. Arnaud L, van Vollenhoven R. Classification criteria. Advanced Handbook of Systemic Lupus Erythematosus: Springer Nature; 2017. p. 28.

3. Tedeschi S, Johnson S, Boumpas D, Daikh D, Diamond B, Doerner T, et al. A Multicriteria Decision Analysis for the Development of New Systemic Lupus Erythematosus Classification Criteria. Arthritis Rheum. 2017;69 (suppl 10).

4. Narula N, Narula T, Abril A. Seizing the clinical presentation in adult onset Still's disease. An extensive literature review. Autoimmun Rev. 2015;14(5):472-7.

5. Arnaud L, van Vollenhoven R. Genetics of SLE. Advanced Handbook of Systemic Lupus Erythematosus: Springer Nature; 2017. p. 28.

6. Ebbo M, Daniel L, Pavic M, Seve P, Hamidou M, Andres E, et al. IgG4-related systemic disease: features and treatment response in a French cohort: results of a multicenter registry. Medicine (Baltimore). 2012;91(1):49-56.

7. Kostine M, Rouxel L, Barnetche T, Veillon R, Martin F, Dutriaux C, et al. Rheumatic disorders associated with immune checkpoint inhibitors in patients with cancer-clinical aspects and relationship with tumour response: a single-centre prospective cohort study. Ann Rheum Dis. 2017.

8. Zeiser R, Blazar BR. Pathophysiology of Chronic Graft-versus-Host Disease and Therapeutic Targets. N Engl J Med. 2017;377(26):2565-79.

9. Frizell AW, Higgins GL, 3rd. Cardiac myxoma as a mimic: a diagnostic challenge. Am J Emerg Med. 2014;32(11):1399-404.

10. Cervera R, Khamashta MA, Font J, Sebastiani GD, Gil A, Lavilla P, et al. Systemic lupus erythematosus: clinical and immunologic patterns of disease expression in a cohort of 1,000 patients. The European Working Party on Systemic Lupus Erythematosus. Medicine (Baltimore). 1993;72(2):113-24.

11. Gilliam JN, Sontheimer RD. Distinctive cutaneous subsets in the spectrum of lupus erythematosus. J Am Acad Dermatol. 1981;4(4):471-5.

12. Biazar C, Sigges J, Patsinakidis N, Ruland V, Amler S, Bonsmann G, et al. Cutaneous lupus erythematosus: first multicenter database analysis of 1002 patients from the European Society of Cutaneous Lupus Erythematosus (EUSCLE). Autoimmun Rev. 2013;12(3):444-54. 13. Bangert JL, Freeman RG, Sontheimer RD, Gilliam JN. Subacute cutaneous lupus erythematosus and discoid lupus erythematosus. Comparative histopathologic findings. Arch Dermatol. 1984;120(3):332-7.

14. Obermoser G, Sontheimer RD, Zelger B. Overview of common, rare and atypical manifestations of cutaneous lupus erythematosus and histopathological correlates. Lupus. 2010;19(9):1050-70.

15. Brown TT, Choi EY, Thomas DG, Hristov AC, Chan MP. Comparative analysis of rosacea and cutaneous lupus erythematosus: histopathologic features, T-cell subsets, and plasmacytoid dendritic cells. J Am Acad Dermatol. 2014;71(1):100-7.

16. Serio I, Arnaud L, Mathian A, Hausfater P, Amoura Z. Can procalcitonin be used to distinguish between disease flare and infection in patients with systemic lupus erythematosus: a systematic literature review. Clin Rheumatol. 2014;33(9):1209-15.

17. Rigante D, Mazzoni MB, Esposito S. The cryptic interplay between systemic lupus erythematosus and infections. Autoimmun Rev. 2014;13(2):96-102.

18. Larsen M, Sauce D, Deback C, Arnaud L, Mathian A, Miyara M, et al. Exhausted cytotoxic control of Epstein-Barr virus in human lupus. PLoS Pathog. 2011;7(10):e1002328. 
19. Picard C, Belot A. Does type-I interferon drive systemic autoimmunity? Autoimmun Rev. 2017;16(9):897-902.

20. Fremond ML, Rodero MP, Jeremiah N, Belot A, Jeziorski E, Duffy D, et al. Efficacy of the Janus kinase 1/2 inhibitor ruxolitinib in the treatment of vasculopathy associated with TMEM173-activating mutations in 3 children. J Allergy Clin Immunol. 2016;138(6):1752-5.

21. Rice GI, Melki I, Fremond ML, Briggs TA, Rodero MP, Kitabayashi N, et al. Assessment of Type I Interferon Signaling in Pediatric Inflammatory Disease. J Clin Immunol. 2017;37(2):123-32.

22. Gavand PE, Serio I, Arnaud L, Costedoat-Chalumeau N, Carvelli J, Dossier A, et al. Clinical spectrum and therapeutic management of systemic lupus erythematosus-associated macrophage activation syndrome: A study of 103 episodes in 89 adult patients. Autoimmun Rev. 2017;16(7):743-9.

23. Henter JI, Horne A, Arico M, Egeler RM, Filipovich AH, Imashuku S, et al. HLH2004: Diagnostic and therapeutic guidelines for hemophagocytic lymphohistiocytosis. Pediatr Blood Cancer. 2007;48(2):124-31.

24. Parodi A, Davi S, Pringe AB, Pistorio A, Ruperto N, Magni-Manzoni S, et al. Macrophage activation syndrome in juvenile systemic lupus erythematosus: a multinational multicenter study of thirty-eight patients. Arthritis Rheum. 2009;60(11):3388-99.

25. Neven B, Magerus-Chatinet A, Florkin B, Gobert D, Lambotte O, De Somer L, et al. A survey of 90 patients with autoimmune lymphoproliferative syndrome related to TNFRSF6 mutation. Blood. 2011;118(18):4798-807.

26. Rieux-Laucat F. What's up in the ALPS. Curr Opin Immunol. 2017;49:79-86.

27. Klemann C, Esquivel M, Magerus-Chatinet A, Lorenz MR, Fuchs I, Neveux N, et al. Evolution of disease activity and biomarkers on and off rapamycin in 28 patients with autoimmune lymphoproliferative syndrome. Haematologica. 2017;102(2):e52-e6.

28. Fischer A, Provot J, Jais JP, Alcais A, Mahlaoui N, members of the CFPIDsg. Autoimmune and inflammatory manifestations occur frequently in patients with primary immunodeficiencies. J Allergy Clin Immunol. 2017;140(5):1388-93 e8.

29. Sopena B, Rivera A, Chamorro A, Freire M, Alende V, Seco E, et al. Clinical association between Kikuchis disease and systemic lupus erythematosus: A systematic literature review. Semin Arthritis Rheum. 2017;47(1):46-52.

30. Kucukardali Y, Solmazgul E, Kunter E, Oncul O, Yildirim S, Kaplan M. KikuchiFujimoto Disease: analysis of 244 cases. Clin Rheumatol. 2007;26(1):50-4.

31. Atwater AR, Longley BJ, Aughenbaugh WD. Kikuchi's disease: case report and systematic review of cutaneous and histopathologic presentations. J Am Acad Dermatol. 2008;59(1):130-6.

32. Dumas G, Prendki V, Haroche J, Amoura Z, Cacoub P, Galicier L, et al. KikuchiFujimoto disease: retrospective study of 91 cases and review of the literature. Medicine (Baltimore). 2014;93(24):372-82.

33. Dorfman RF, Berry GJ. Kikuchi's histiocytic necrotizing lymphadenitis: an analysis of 108 cases with emphasis on differential diagnosis. Semin Diagn Pathol. 1988;5(4):329-45.

34. Fajgenbaum DC, Uldrick TS, Bagg A, Frank D, Wu D, Srkalovic G, et al. International, evidence-based consensus diagnostic criteria for HHV-8-negative/idiopathic multicentric Castleman disease. Blood. 2017;129(12):1646-57.

35. Fajgenbaum DC, van Rhee F, Nabel CS. HHV-8-negative, idiopathic multicentric Castleman disease: novel insights into biology, pathogenesis, and therapy. Blood. 2014;123(19):2924-33.

36. Lunning MA, Vose JM. Angioimmunoblastic T-cell lymphoma: the many-faced lymphoma. Blood. 2017;129(9):1095-102. 
37. Lachenal F, Berger F, Ghesquieres H, Biron P, Hot A, Callet-Bauchu E, et al. Angioimmunoblastic T-cell lymphoma: clinical and laboratory features at diagnosis in 77 patients. Medicine (Baltimore). 2007;86(5):282-92.

38. Marotte H, Gineyts E, Miossec P. Prolidase deficiency: a rare aetiology of arthritis. Joint Bone Spine. 2010;77(1):88-9.

39. Kurien BT, D'Sousa A, Bruner BF, Gross T, James JA, Targoff IN, et al. Prolidase deficiency breaks tolerance to lupus-associated antigens. Int J Rheum Dis. 2013;16(6):674-80. 
Table 1 Main differential diagnoses of SLE (SLE mimickers)

\begin{tabular}{|c|c|}
\hline Cutaneous mimickers & Depending on CLE subtypes : see table 2 \\
\hline Other connective tissue diseases & $\begin{array}{l}\text { Sjögren (SSA+), dermatomyositis (rash), } \\
\text { Mixed Connective Tissue Disease }\end{array}$ \\
\hline Infectious diseases & $\begin{array}{l}\text { Endocarditis, hepatitis A, B, C, E, parvovirus } \\
\text { B19, HIV, EBV, CMV, Lyme, disseminated } \\
\text { gonococcal arthritis, toxoplasmosis, } \\
\text { histoplasmosis, mycobacterial diseases, tinea } \\
\text { faciei, visceral leishmaniasis, Whipple's } \\
\text { disease. }\end{array}$ \\
\hline Hematological malignancies & $\begin{array}{l}\text { Hodgkin's lymphoma, myelodysplastic } \\
\text { syndromes, Angioimmunoblastic T-cell } \\
\text { lymphoma (See dedicated section in this } \\
\text { review) }\end{array}$ \\
\hline Solid tumors and paraneoplastic syndromes & $\begin{array}{l}\text { Thymoma, carcinoma of the lung, breast, and } \\
\text { ovary with paraneoplastic syndromes. }\end{array}$ \\
\hline Meigs and Pseudo-Meigs syndrome & $\begin{array}{l}\text { Pseudo Meigs syndrome: pleural effusion, } \\
\text { ascites associated with an ovarian tumor that } \\
\text { is not a fibroma or a fibroma-like tumor }\end{array}$ \\
\hline Multiple sclerosis & $\begin{array}{l}5 \text { to } 10 \% \text { percent of MS patients have } \\
\text { antinuclear antibodies }\end{array}$ \\
\hline Castleman's disease & See dedicated section in this review \\
\hline Interferonopathies (monogenic SLE) & See dedicated section in this review \\
\hline $\begin{array}{l}\text { Still's disease (and other autoinflammatory } \\
\text { diseases) }\end{array}$ & Reviewed in depth in (4) \\
\hline $\begin{array}{l}\text { Evans' syndrome (with primary immune } \\
\text { deficiency) }\end{array}$ & See dedicated section in this review \\
\hline Complement deficiency & Reviewed in depth in (5) \\
\hline Schizophrenia and other psychoses & $\begin{array}{l}\text { Psychosis with antinuclear antibodies } \\
\text { induced by neuroleptics }\end{array}$ \\
\hline Kikuchi's disease & See dedicated section in this review \\
\hline IgG4-related disease & Reviewed in depth in (6) \\
\hline Chilblains (cold-induced) & Chilblain-like cutaneous lupus \\
\hline $\begin{array}{l}\text { Ackerman's syndrome and erythema } \\
\text { elevatum diutinum with polyarthritis }\end{array}$ & $\begin{array}{l}\text { Ackerman's: Interstitial granulomatous } \\
\text { dermatitis with polyarthritis }\end{array}$ \\
\hline $\begin{array}{l}\text { Drug-induced lupus and drug-induced } \\
\text { polyarthritis }\end{array}$ & Including checkpoint inhibitors (7) \\
\hline Graft-versus-host disease & Reviewed in depth in (8) \\
\hline Systemic manifestations of atrial myxoma & Reviewed in depth in (9) \\
\hline Prolidase deficiency & See dedicated section in this review \\
\hline
\end{tabular}


Table 2. Main differential diagnoses of LE-specific skin disease

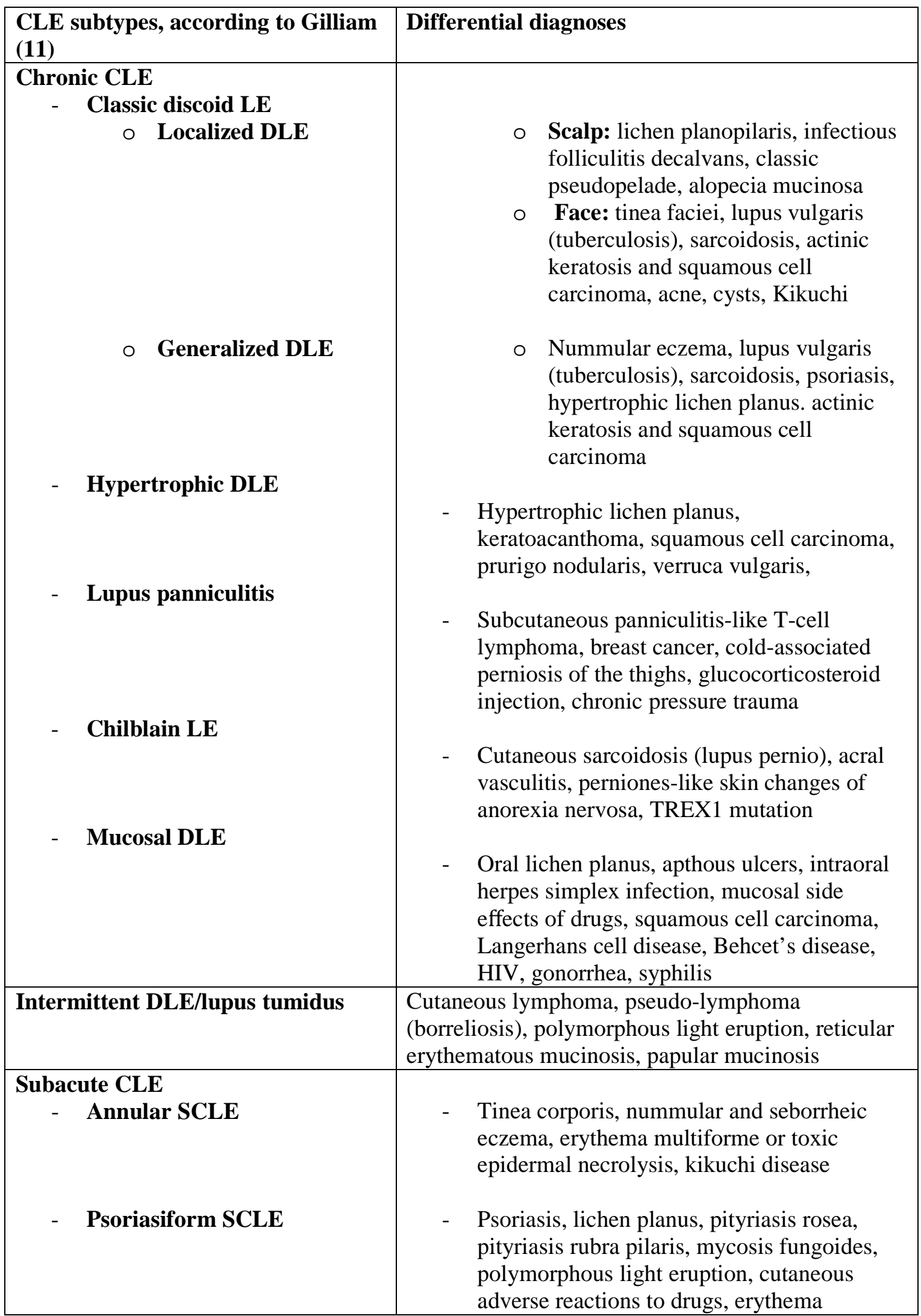




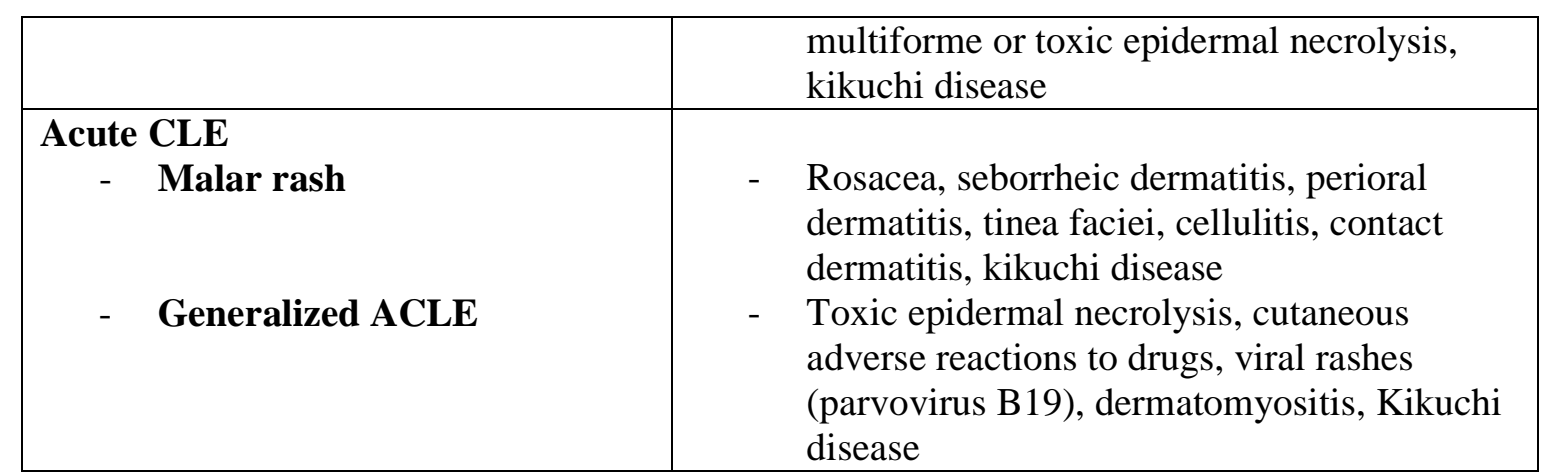

CLE: Cutaneous Lupus Erythematosus; DLE: Discoid Lupus Erythematosus; SCLE:

Subacute Cutaneous Lupus Erythematosus; ACLE: Acute Cutaneous Lupus Erythematosus. 
Table 3. Type I interferonopathies associated to SLE

\begin{tabular}{|c|c|c|c|c|c|}
\hline Gene/Protein & $\begin{array}{l}\text { Age at } \\
\text { onset }\end{array}$ & $\begin{array}{l}\text { Protein } \\
\text { function }\end{array}$ & $\begin{array}{l}\text { Pathway } \\
\text { related } \\
\text { to type I } \\
\text { IFN } \\
\text { signaling }\end{array}$ & $\begin{array}{c}\text { Inheritan } \\
\text { ce }\end{array}$ & $\begin{array}{c}\text { Main } \\
\text { clinical } \\
\text { features in } \\
\text { addition to } \\
\text { SLE }\end{array}$ \\
\hline TREX1/TREX1 & $\begin{array}{l}\text { Neonate } \\
\text { s- } \\
\text { children } \\
\text { adults }\end{array}$ & $\begin{array}{c}\text { Deoxyribonuclea } \\
\text { se }\end{array}$ & $\begin{array}{l}\text { Cytosolic } \\
\text { DNA }\end{array}$ & $\begin{array}{l}\text { Autosomal } \\
\text { Recessive }\end{array}$ & $\begin{array}{l}\text { Chilblain, } \\
\text { glaucoma, } \\
\text { mental } \\
\text { retardation }\end{array}$ \\
\hline SAMHD1/SAMHD1 & $\begin{array}{l}\text { Neonate } \\
\text { s, } \\
\text { children }\end{array}$ & $\begin{array}{l}\text { Control of dNTP } \\
\text { pool ( } \pm \text { nuclease })\end{array}$ & $\begin{array}{l}\text { Cytosolic } \\
\text { DNA } \\
\text { ( } \pm \text { cytosoli } \\
\text { c RNA) }\end{array}$ & $\begin{array}{l}\text { Autosomal } \\
\text { Recessive }\end{array}$ & $\begin{array}{l}\text { Chilblain, } \\
\text { Moya- } \\
\text { Moya, } \\
\text { Glaucoma, } \\
\text { mental } \\
\text { retardation }\end{array}$ \\
\hline TMEM173/STING & $\begin{array}{c}\text { Children } \\
\text {, adults }\end{array}$ & $\begin{array}{l}\text { Adaptor of } \\
\text { cGAS }\end{array}$ & $\begin{array}{l}\text { Cytosolic } \\
\text { DNA } \\
\text { ( } \pm \text { cytosoli } \\
\text { c RNA) }\end{array}$ & $\begin{array}{c}\text { Autosomal } \\
\text { dominant }\end{array}$ & $\begin{array}{c}\text { Interstitial } \\
\text { pneumopath } \\
y, \\
\text { lung } \\
\text { fibrosis, } \\
\text { skin } \\
\text { vasculitis, }\end{array}$ \\
\hline $\begin{array}{l}\text { RNASEH2A/RNASEH } \\
\text { 2A } \\
R N A S E H 2 B / R N A S E H \\
\text { 2B } \\
\text { RNASEH2C/RNASEH } \\
\text { 2C }\end{array}$ & $\begin{array}{l}\text { Neonatal } \\
\text { children }\end{array}$ & Ribonuclease & $\begin{array}{l}\text { Cytosolic } \\
\text { RNA:DN } \\
\text { A hybrids }\end{array}$ & $\begin{array}{l}\text { Autosomal } \\
\text { Recessive }\end{array}$ & $\begin{array}{c}\text { Paraparesis, } \\
\text { mental } \\
\text { retardation }\end{array}$ \\
\hline IFIH1/MDA5 & $\begin{array}{l}\text { Neonate } \\
\text { s, } \\
\text { children, } \\
\text { adults }\end{array}$ & dsRNA sensor & $\begin{array}{l}\text { Cytosolic } \\
\text { RNA }\end{array}$ & $\begin{array}{c}\text { Autosomal } \\
\text { dominant }\end{array}$ & $\begin{array}{c}\text { Paraparesis, } \\
\text { glaucoma, } \\
\text { vasculitis }\end{array}$ \\
\hline DDX58/RIG-I & $\begin{array}{c}\text { Children } \\
\text {, adults }\end{array}$ & dsRNA sensor & $\begin{array}{l}\text { Cytosolic } \\
\text { RNA }\end{array}$ & $\begin{array}{c}\text { Autosomal } \\
\text { dominant }\end{array}$ & $\begin{array}{l}\text { Glaucoma, } \\
\text { Singleton- } \\
\text { Merten } \\
\text { Syndrome }\end{array}$ \\
\hline ACP5/TRAP & $\begin{array}{l}\text { Neonate } \\
\text { s, } \\
\text { children, } \\
\text { adults }\end{array}$ & $\begin{array}{c}\text { Phosphatase } \\
\text { activity }\end{array}$ & Unknown & $\begin{array}{l}\text { Autosomal } \\
\text { Recessive }\end{array}$ & $\begin{array}{l}\text { SPENCD, } \\
\text { cytopenias, } \\
\text { vasculitis, } \\
\text { growth } \\
\text { retardation }\end{array}$ \\
\hline$C 1 Q A, B, C / \mathrm{C} 1 \mathrm{QA}, \mathrm{B}, \mathrm{C}$ & $\begin{array}{c}\text { Children } \\
\text {, adults }\end{array}$ & $\begin{array}{c}\text { Canonical } \\
\text { complement } \\
\text { pathway activity }\end{array}$ & Unknown & $\begin{array}{l}\text { Autosomal } \\
\text { Recessive }\end{array}$ & $\begin{array}{l}\text { Infections, } \\
\text { skin lesions }\end{array}$ \\
\hline
\end{tabular}

IFN: Interferon, SPENCD: Spondyloenchondrodysplasia, dNTP: Deoxynucleotide, cGAS: cyclic GMP-AMP Synthase. 
Table 4. Typical features of MAS observed in 103 episodes among 89 adult SLE patients, adapted from (22)

\begin{tabular}{|l|c|}
\hline Clinical and laboratory features & $\begin{array}{c}\text { Frequency } \\
\text { (\% of episodes })\end{array}$ \\
\hline Fever $>38.0^{\circ} \mathrm{C}$ & $100 \%$ \\
\hline Splenomegaly & $27 \%$ \\
\hline Hepatomegaly or adenomegaly & $37 \%$ \\
\hline Haemophagocytosis (bone marrow) & $61 \%$ \\
\hline Elevated AST & $95 \%$ \\
\hline Elevated LDH & $92 \%$ \\
\hline Hyperferritinemia $>500 \mu \mathrm{g} / \mathrm{L}$ & $96 \%$ \\
\hline CRP $>5 \mathrm{mg} / \mathrm{dL}$ & $84 \%$ \\
\hline Increased PCT level $(>0.25 \mu \mathrm{g} / \mathrm{L})$ & $84 \%$ \\
\hline Neutropenia $(<1000 / \mathrm{mm} 3)$ & $46 \%$ \\
\hline Anemia $(<9 \mathrm{~g} / \mathrm{dL})$ & $60 \%$ \\
\hline Thrombocytopenia $(<100 \mathrm{G} / \mathrm{l})$ & $54 \%$ \\
\hline Hypofibrinogenemia $(<1.5 \mathrm{~g} / \mathrm{dL})$ & $9 \%$ \\
\hline Hypertriglyceridemia & $58 \%$ \\
\hline Lymphopenia $<1000 / \mathrm{mm} 3$ & $91 \%$ \\
\hline Low C3 & $56 \%$ \\
\hline Positive anti-DNA Ab & $63 \%$ \\
\hline
\end{tabular}




\section{FIGURES}

Figure 1. Typical acute lupus erythematosus (ACLE): vespertilio and erosive cheilitis.

Figure 2. Mild rosacea: erythema and rare papulo-pustular lesions of the cheeks.

Figure 3. Seborrheic dermatitis: well demarcated erythema-squamous patches around the nose, the eyebrows and the forehead.

Figure 4. Dermatomyositis: Erythematous and telangiectatic patches, heliotrope eyelids, erythematous papules of the hand sparing the interphalangeal skin. 


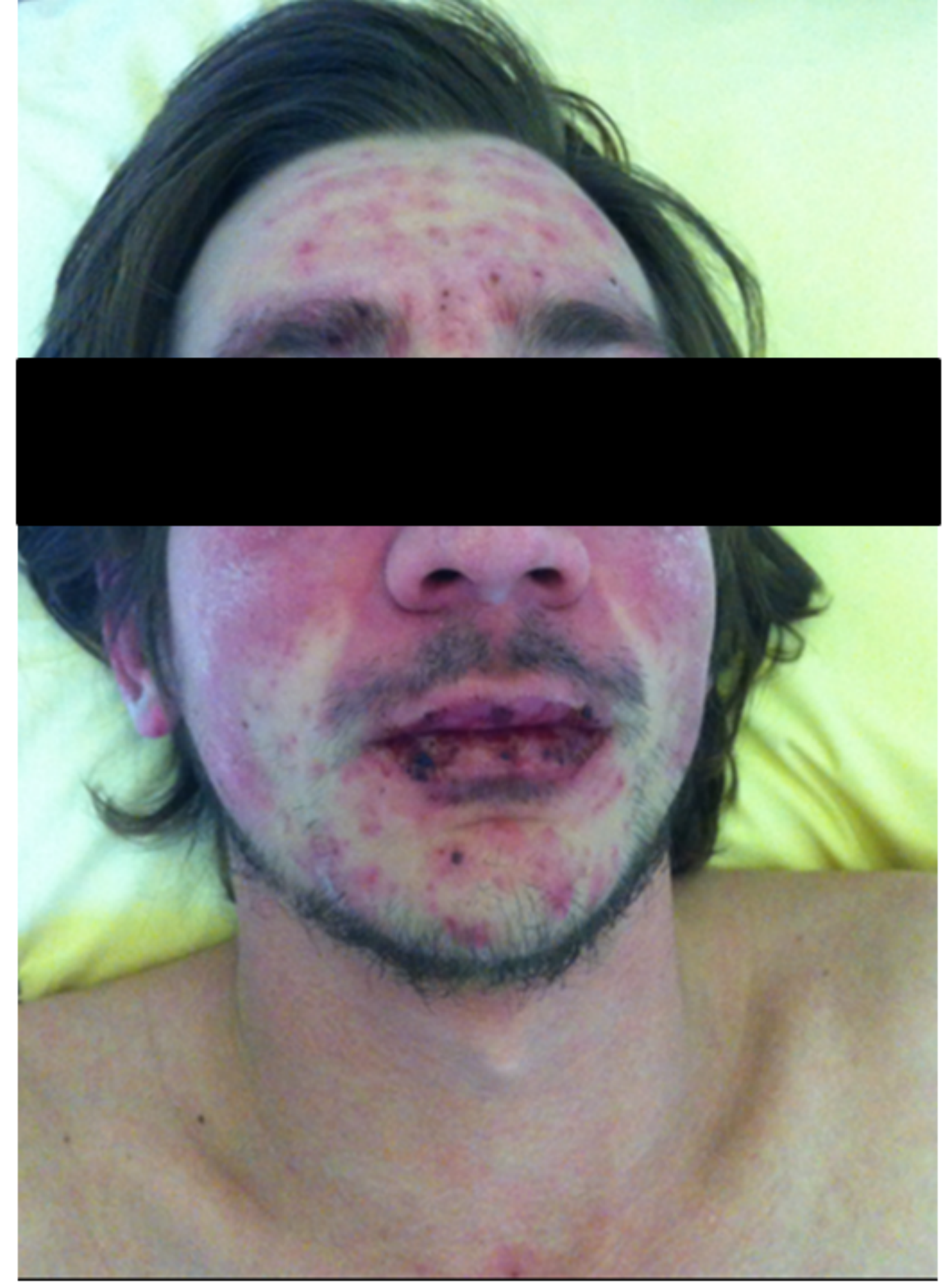




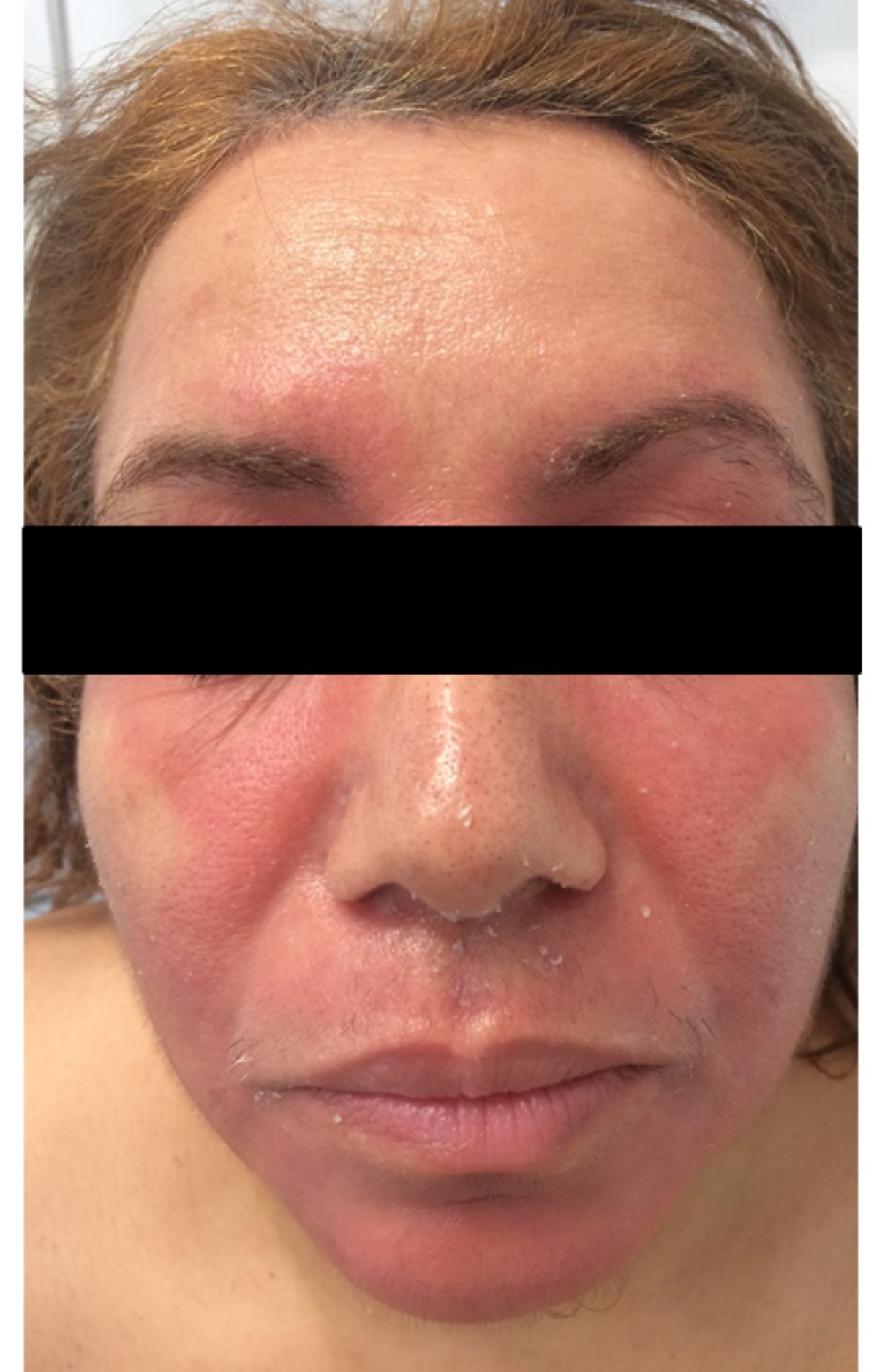


